\title{
Relato de experiência: a atuação do psicólogo no CRAS e sua contribuição para o fortalecimento dos direitos sociais
}

Experience report: the psychologist's performance and its contributions for the strengthening of social rights

Relato de experiencia: la actuación del psicólogo del CRAS y su contribución al fortalecimiento de los derechos sociales

Nivia Lúcia de Andrade Oliveira* Marilia Noronha Costa do Nascimento ${ }^{* *}$ Rafaella Lopes Araujjo ${ }^{* * *}$ Ilana Lemos de Paiva ${ }^{* * *}$

\begin{abstract}
Resumo
Este relato tem como objetivo discutir as contribuições da Psicologia para a atuação no Centro de Referência de Assistência Social (CRAS), por meio de uma experiência de estágio curricular ancorada na perspectiva da Psicologia comunitária. Desenvolveu-se uma série de atividades: acolhimento; preenchimento de cadastro de famílias; estratégias de busca ativa: visitas domiciliares, mapeamento das redes socioassistencial e intersetorial, listagens dos beneficiários em descumprimento das condicionalidades do Programa Bolsa Família (PBF) e dos usuários do Programa de Erradicação do Trabalho Infantil (PETI); atividade socioeducativa; articulação com as redes socioassistencial e intersetorial; sistematização das informações. Assim, acredita-se que a atuação do psicólogo, por meio dessas ações, contribuiu para o fortalecimento da garantia de direitos da população atendida. Considera-se que a perspectiva teórica adotada potencializou a realização de um trabalho em consonância com as diretrizes da Política Nacional de Assistência Social (PNAS).
\end{abstract}

Palavras-chave: Psicologia comunitária. Assistência Social. Proteção social básica. CRAS.

\footnotetext{
Texto recebido em abril de 2014 e aprovado para publicação em dezembro de 2015

Mestra pelo Programa de Pós-Graduação em Psicologia da Universidade Federal do Rio Grande do Norte (UFRN), psicóloga graduada pela UFRN. Endereço: Alameda das Mansões, n. ${ }^{\circ}$ 3693, bl. 35, ap. 203 - Condomínio Bairro Latino, Candelária, Natal-RN, Brasil. CEP: 59064-902.E-mail: psiniviaandrade@gmail.com.

* Mestra pelo Programa de Pós-Graduação em Psicologia da Universidade Federal do Rio Grande do Norte (UFRN), psicóloga graduada pela UFRN. Endereço: Alameda das Mansōes, n. ${ }^{\circ}$ 3693, bl. 10, ap. 304 - Condomínio Bairro Latino, Candelária, Natal-RN, Brasil. CEP: 59064-902. E-mail: lilanoronha@hotmail.com.

*** Mestranda do Programa de Pós-Graduação em Psicologia da Universidade Federal do Rio Grande do Norte (UFRN), psicóloga graduada pela UFRN. Endereço: Rua Jacarandá, n.o 7909 - Bairro Pitimbu, Conjunto Cidade Satélite, Natal-RN, Brasil. CEP: 59067-530.E-mail: rafaellalopesa@hotmail.com.

**** Doutora pelo Programa Integrado de Pós-Graduação em Psicologia Social da Universidade Federal do Rio Grande do Norte e da Universidade Federal da Paraíba (UFRN/UFPB), professora adjunta do Departamento de Psicologia da UFRN. Endereço: Avenida Senador Salgado Filho, n. ${ }^{\circ}$ 3000, Campus Universitário, BR-101 - Lagoa Nova, Natal-RN, Brasil. CEP: 59072-970. E-mail: ilanapaiva@hotmail.com.
} 


\begin{abstract}
This report aims to discuss the contributions of Psychology to the actions in Centro de Referência de Assistência Social (CRAS) from a curricular internship experience anchored in a Community Psychology perspective. A series of activities were developed: reception; filling out registration of families; screening strategies: home visits, mapping of social assistance and inter-sectoral networks, listings of beneficiaries in non-compliance with the conditions of the Programa Bolsa Família (PBF) and of the users of the Programa de Erradicação do Trabalho Infantil (PETI); socio-educational activity; conjunction with social assistance and inter-sectoral networks; systematization of information. Thus, it is believed that the psychologist's performance, through these actions, contributed to the strengthening of the guarantee of the rights of the population. It was observed that the adopted theoretical perspective has enhanced the performance of work in accordance with the guidelines of the Política Nacional de Assistência Social (PNAS).
\end{abstract}

Keywords: Community psychology. Social Assistance. Basic Social protection. CRAS.

\title{
Resumen
}

Este relato tiene como objetivo discutir las contribuciones da la Psicología para el trabajo en el Centro de Referencia de Asistencia Social (CRAS), a través de una experiencia de prácticas curriculares, apoyada en la perspectiva de la Psicología Comunitaria. Fueron desarrolladas diversas actividades: acogida; inscripción en el registro de las familias; estrategia de búsqueda activa; visitas a domicilio; mapeo de las redes de asistencia social e intersectorial; listado de los beneficiarios en incumplimiento de la condiciones del Programa Bolsa Família (PBF) y de los usuarios del Programa de Erradicación del Trabajo Infantil (PETI); actividades socioeducativas; articulación con las redes de asistencia social e intersectorial y sistematización de informaciones. Así, se cree que la actuación del psicólogo, por medio de estas acciones, contribuyó para el fortalecimiento de la garantía de los derechos da población asistida. Se considera que la perspectiva adoptada potenció la realización de un trabajo en consonancia con las directrices de la Política Nacional de Asistencia Social (PNAS).

Palabras clave: Psicología comunitaria. Asistencia Social. Protección social básica. CRAS.

\section{Introdução}

objetivo deste trabalho é discutir a atuação do psicólogo no Centro de
Referência de Assistência Social (CRAS), com base em uma experiência
de estágio supervisionado com duração de um ano, orientada para o 
fortalecimento da garantia dos direitos sociais de uma comunidade localizada no interior do Estado do Rio Grande do Norte. Trata-se de um relato de experiência em que foram destacadas as ações desenvolvidas nesse período, levando-se em consideração como alguns conceitos da Psicologia comunitária subsidiaram a sua realização, bem como quais possíveis diálogos entre a atuação do psicólogo e a Política Nacional de Assistência Social (PNAS).

Considera-se pertinente contextualizar o campo de intervenção (o CRAS) com os determinantes históricos e políticos que o circundam, bem como o processo de inserção da Psicologia nesse espaço. Para tanto, buscaram-se algumas reflexões de ordem macroestrutural, a fim de obter uma melhor compreensão do campo.

A inserção da Psicologia nas políticas sociais tem o campo da saúde como marco de entrada do psicólogo a partir da década de 1980, no contexto de reordenamento da seguridade social do Brasil, após o período da ditadura militar. A entrada da profissão no campo do bem-estar social remete a Psicologia para a ação direcionada às sequelas da "questão social", compreendida como manifestação da contradição fundamental capital x trabalho. Suas manifestações mais imediatas se traduzem por meio de desigualdades sociais, desemprego, fome, doenças, pobreza, etc. Diante do agravamento dessas manifestaçôes, o Estado intervém por meio das políticas sociais (Paulo Netto, 2001). Assim, a política social atende à "questão social" de forma setorizada, transmutando-se em políticas sociais, respondendo-a de modo fragmentado (Yamamoto, 2003).

A compreensão da realidade social, a partir da contradição fundamental inerente a esse modo de produção (Kosik, 2002), permite apreender o caráter contraditório da política social: ao mesmo tempo em que garante direitos sociais, também mantém as relações sociais de reprodução capitalista. Dessa forma, temos que, embora a "questão social" seja única, o ataque às suas consequências se faz de forma parcializada e fragmentada; intervêm-se na pobreza, na fome, na educação, na saúde, etc., de forma desarticulada, com investimentos distintos e protagonismo variável em razão de circunstâncias específicas (mobilização, tensionamentos, reivindicações, entre outros) (Santos, 1987). Nesse sentido, sendo gestadas dentro dos marcos do modo de produção capitalista, não cabe às políticas, por essência, superar as condições de exploração que são base dessa estrutura societária e suas consequências. A Assistência Social, na condição de política pública, reproduz essa contradição. Assim, as ações socioassistenciais podem ser problematizadas com base nessa perspectiva, pois são forjadas dentro dos marcos do capital, contribuindo para sua manutenção, ainda que possibilitem acesso à seguridade social. 
A Assistência Social, tradicionalmente, tem lidado com as expressōes mais radicalizadas da "questão social", por meio de ações compensatórias e parciais no alívio imediato da pobreza. Por esse formato, sua função se tornou historicamente paliativa diante de situações extremas de destituição, vulnerabilidade e risco social, tendo como lócus de intervenção as famílias que se encontram nessa situação (Paiva, 2006). Contextualizando-a com a realidade do Brasil, um país marcado por altos índices de pobreza $-2,3 \%$ da população vive em condições de extrema pobreza e 4,8\% em condições de pobreza (Instituto de Pesquisa Econômica Aplicada [IPEA], 2010) - a Assistência Social está inserida num contexto de forte pauperização da população.

Um breve percurso histórico do campo da política social no Brasil sinaliza uma inflexão, em 1988, ano em que a Assistência Social passou a compor o tripé da Seguridade Social, constituído também pela Previdência Social e pela Saúde. A Lei Orgânica da Assistência Social (LOAS) (Lei Federal n. ${ }^{\circ}$ 8.742), promulgada em 1993, assegura a Assistência Social como direito do cidadão e dever do Estado, política não contributiva, e provimento de mínimos sociais. Tem como principais objetivos conferir proteção à família, à maternidade, à infância, à adolescência e à velhice; a promoção da integração ao mercado de trabalho; a garantia de um salário mínimo de benefício mensal à pessoa portadora de deficiência e ao idoso que comprovem a incapacidade de prover a própria manutenção. Embora a LOAS institua a supremacia do Estado como responsável pela sua execução, desde então, houve pouco progresso na política, já que, na contramão, o governo federal lançou, em 1995, o Programa Comunidade Solidária, retomando a matriz do voluntarismo e, consequentemente, afastando do Estado a sua responsabilidade ao repassá-la para a iniciativa privada (Couto, 2010).

Assim, a Assistência Social tem seu avanço retomado em 2004, com a promulgação da Política Nacional de Assistência Social (PNAS) (Brasil, 2004), instituindo um novo modelo de gestão, que é materializado a partir da implantação do Sistema Único de Assistência Social (SUAS), em 2005. Nesse cenário, ressaltase a centralidade na família, em que a matricialidade sociofamiliar é um dos eixos estruturantes do SUAS (Mioto, 2008).

O SUAS instituiu a proteção social em dois patamares, a básica e a especial: a primeira é operacionalizada nos CRAS, atuando na prevenção de situações de vulnerabilidade social; a segunda nos centros de referência especializados de Assistência Social (CREAS), atuando nas situações em que a violação de direito já tenha sido instaurada (Brasil, 2004). 
A proteção social básica destina-se prioritariamente aos usuários do Programa Bolsa Família (PBF), tendo como missão executar o Serviço de Proteção e Atendimento Integral à Família (PAIF), ofertado por meio dos serviços socioassistenciais, socioeducativos e de preparação para inclusão produtiva (Brasil, 2006). Assim, entende-se o CRAS como um equipamento estatal que tem como objetivos principais prevenir situações de risco, por meio do desenvolvimento de potencialidades e aquisições, e fortalecer vínculos familiares e comunitários.

A PNAS (Brasil, 2004) recomenda que o CRAS desenvolva serviços, programas e projetos locais de acolhimento, socialização e convivência. Outra função primordial é realizar um ativo serviço de mapeamento da rede pública e privada de atenção à população, a fim de sistematizar as informações obtidas e articular as demais políticas sociais.

Ressalta-se ainda que a PNAS/SUAS cria uma série de serviços que extrapolam os referenciais técnicos do Serviço Social, profissão que tradicionalmente esteve ligada à Assistência Social, de modo que demanda a inserção de outros profissionais para operacionalizá-los. Dessa maneira, a conformação atual da Assistência Social suscita desafios para a formulação de metodologias de trabalho socioassistencial que forneçam subsídios para a atuação em equipes multidisciplinares. É nesse cenário que os psicólogos ganham espaço de inserção na Assistência Social como um profissional cuja imagem é de uma competência potencial para solucionar questôes referentes à subjetividade, à coletividade e ao universo particular dos sujeitos em situação de vulnerabilidade social ou cujos direitos foram violados.

\section{Contextualização do campo de intervenção}

A perspectiva teórico-metodológica que orientou esta experiência está fundamentada nos princípios da Psicologia comunitária. Segundo Montero (2004), a Psicologia comunitária tem como objeto de estudo e intervenção os fatores psicossociais que desenvolvem e fomentam o fortalecimento dos sujeitos, no âmbito individual e social, para solucionar as problemáticas que vivenciam. A autora aponta que a Psicologia comunitária se ocupa dos fenômenos psicossociais e sua relação com os processos comunitários, levando em conta o contexto social e cultural em que surgem. Compreende a comunidade como um espaço dinâmico e composto por agentes ativos, levando em consideração, ainda, as potencialidades da comunidade, a diversidade cultural presente em cada uma delas e as relações entre as pessoas e o meio em que vivem.

Com base nessa perspectiva, ao entrar em contato com a comunidade e progressivamente familiarizar-se com a sua dinâmica, foi possível identificar algumas de suas características. O Município se localiza no interior do Estado do 
Rio Grande do Norte, é considerado de pequeno porte I (até 20 mil habitantes) e tem uma população de 3.129 habitantes em condição de extrema pobreza, o que corresponde a $47,4 \%$ da população total (Bremaeker, 2010).

A comunidade também apresentava alguns dispositivos que potencializavam o seu fortalecimento:

a) a Pastoral da Criança tinha um trabalho consolidado de orientação junto às mães de crianças de $0 \mathrm{a} 6$ anos, atendendo a famílias que se encontravam na área urbana, bem como em comunidades rurais;

b) a Associação das Costureiras havia retomado suas atividades;

c) e o Grupo dos Idosos também era bastante consolidado no Município e, desde a implantação do CRAS, em 2005, esse estabelecimento passou a facilitar a manutenção do grupo. Esse dispositivo constituía um espaço de convivência sem demarcação temporal fixa, de modo que suas atividades eram realizadas durante o ano todo. Como será visto adiante, outros grupos também passaram a ser coordenados pela equipe do CRAS, como foi o caso do Grupo de Gestantes e do Grupo de Mães, mas com periodicidade delimitada.

O CRAS desse Município era composto por uma equipe de cinco profissionais: uma coordenadora, uma assistente social, uma psicóloga, uma assistente de serviços gerais e uma estagiária de Psicologia. Essa instituição era referência para os demais programas da Assistência Social do Município, como o Projovem Adolescente e o Programa de Erradicação do Trabalho Infantil (PETI). As equipes que desenvolviam trabalhos nesses dois programas realizavam o seu planejamento junto ao CRAS, solicitando, ainda, um suporte para a construção de algumas atividades. Já em relação à articulação do CRAS com os demais setores, observou-se um processo que ainda estava em construção, visto que desenvolver ações intersetoriais é mais desafiador devido à fragmentação da política social.

No tocante ao trabalho em equipe, alguns membros apresentaram uma perspectiva mais tradicional e conservadora de Assistência Social, circunscrita ao atendimento emergencial. Em contraponto, esse espaço também contava com profissionais que defendiam uma concepção de assistência marcada por contradiçóes, em que o assistencial transitava entre as órbitas do favor e do direito, podendo se constituir também num espaço de protagonismo social, desencadeando, assim, distintas formas de atuação a partir da perspectiva de assistência social de cada profissional. Essa distinção teórico-metodológica gerava pontos de problematização nas relações de trabalho da equipe do CRAS. 


\section{A intervenção: percurso metodológico, atividades realizadas e discussão}

Por se tratar de um relato de experiência, compreende-se que o percurso metodológico da intervenção se configura por meio das ações que foram realizadas no campo, embasadas nas contribuiçôes do campo da Psicologia comunitária, bem como as articulações possíveis com a Política Nacional da Assistência Social, durante 12 meses de estágio na comunidade. Assim, as principais atividades desenvolvidas foram: acolhimento; preenchimento de cadastro; estratégias de busca ativa: mapeamento da rede, listagens e visitas domiciliares; atividade socioeducativa; articulação com a rede socioassistencial e intersetorial; fortalecimento da rede; e sistematização das informações. A seguir, apresenta-se o detalhamento de cada atividade.

\section{$\mathrm{O}$ acolhimento e o preenchimento de cadastro}

O acolhimento se caracterizava pela escuta da demanda espontânea que chegava à instituição. Operacionalizava-se desde a escuta do usuário que chegava em busca de informações gerais, por exemplo, saber onde era realizado o cadastro para inserção no PBF, até denúncias e solicitações de atendimento com a assistente social ou com a psicóloga.

A partir do acolhimento, não se identificava apenas a demanda do usuário, mas também se investigava a inserção da família nos programas sociais, os devidos encaminhamentos para outros serviços, caso fosse necessário, e a situação cadastral da família na instituição. O preenchimento de cadastro mostrou-se instrumento potencial para conhecer as condições materiais de existência das famílias, visto que eram recolhidas suas características socioeconômicas, tornando-se um recurso fundamental para contextualização da demanda trazida pelo usuário.

$\mathrm{O}$ acolhimento também demandava outras ações da equipe, principalmente no que diz respeito aos encaminhamentos. Assim, a busca ativa era uma atividade primordial para o andamento do trabalho, constituindo-se como uma importante ferramenta para a ação preventiva da proteção social básica (um dos principais objetivos do CRAS), pois se compreendia melhor a realidade social para nela atuar, envolvendo um movimento proativo da equipe na comunidade (Brasil, 2009).

\section{A busca ativa e suas estratégias}

As atividades de busca ativa desenvolvidas pela equipe de Psicologia referemse à busca de listagens, mapeamento da rede e visitas domiciliares. Na instituição em questão, a busca de informações das famílias do território de atuação do 
CRAS, provenientes do Cadastro Único de Programas Sociais, realizou-se com a solicitação das listagens dos beneficiários do PBF (entre estes, aqueles que se encontravam em situação de descumprimento das condicionalidades) e usuários do PETI. Outras informações foram solicitadas: especificamente à Secretaria Municipal de Educação, a relação das escolas existentes no Município, com seus respectivos diretores, vice-diretores e coordenadores; bem como listagem dos alunos beneficiários do PBF, por escola. Essa ação teve o intuito de levantar uma série de dados sobre a população em situação de vulnerabilidade social para sistematizar o conhecimento do território e, consequentemente, estabelecer o foco de intervenção do CRAS.

O mapeamento também se constituiu numa atividade fundamental para a atuação do psicólogo nesse espaço. Segundo a PNAS (Brasil, 2004), uma das funções primordiais do CRAS é realizar um ativo serviço de mapeamento da rede pública e privada, a fim de sistematizar as informações obtidas para encaminhar a população local para as demais políticas sociais.

Entende-se por mapeamento a identificação da cobertura de rede prestadora de serviços no território de abrangência do CRAS, bem como das redes de apoio informais existentes no território como lideranças comunitárias, associações de bairro, etc. (Brasil, 2009). Assim, foram identificados tais dispositivos na comunidade: Pastoral da Criança, Associação das Costureiras, Grupo dos Idosos, além da rede socioassistencial e intersetorial. A primeira se configurava por meio do Projovem, do PETI e do Conselho Tutelar; a segunda, por meio da Estratégia da Saúde da Família e pelas escolas. O fato de a comunidade se localizar no interior do Estado concorreu para o mapeamento de serviços em municípios vizinhos e na capital, a fim de ampliar a capacidade de acesso aos serviços demandados pela população.

Uma das formas de o CRAS se efetivar como porta de entrada da garantia de direitos é por meio do encaminhamento do usuário à rede socioassistencial e intersetorial. No decorrer do ano, foram realizados vários encaminhamentos para as mais variadas instituiçōes. No entanto a contrarreferência se mostrou extremamente frágil do ponto de vista da articulação das instituições envolvidas. Além disso, a maioria das instituições acionadas se encontrava sobrecarregada pela grande quantidade de casos atendidos. É importante sinalizar que existe um hiato entre as necessidades da população e a oferta dos serviços pelas políticas sociais, de modo que muitos casos ficam sem a assistência necessária para o seu acompanhamento e avanço. 
A estratégia das visitas domiciliares também foi uma ação importante para a realização da busca ativa. Geralmente aconteciam por causa de denúncias da comunidade em relação às situaçôes de vulnerabilidades, como a fragilidade dos vínculos na família. A maioria dessas denúncias envolvia a criança, o adolescente ou o idoso. Para a Psicologia comunitária, a visita domiciliar é um recurso psicossocial que protege a família mediante situações de vulnerabilidade, tendo como objetivo central potencializar a capacidade de cuidado. Permite ainda ao profissional identificar melhor as demandas e atuar em coerência com as necessidades concretas das famílias (Gracia, 2007). As visitas realizadas na comunidade em questão dialogavam também com a política de Assistência Social, visto que pretendeu desenvolver potencialidades de cuidado destinadas à criança, ao adolescente e ao idoso, ao fortalecer os vínculos familiares.

\section{O trabalho socioeducativo com os grupos}

Outra atividade realizada durante a experiência foi o trabalho socioeducativo com os grupos formados durante o ano de trabalho nesta comunidade. O CRAS dava suporte aos grupos de idosos, gestantes, mães do PETI e à Associação das Costureiras. Segundo o Ministério do Desenvolvimento Social e Combate à Fome, o trabalho socioeducativo com os grupos deve levar em consideração os ciclos de vida de seus participantes, seu ritmo de desenvolvimento e suas referências culturais. (Brasil, 2006)

O grupo dos idosos funcionava em caráter continuado, os encontros eram semanais e aconteciam nas próprias instalações do CRAS, contando com uma participação em média de 20 idosos, composto majoritariamente por mulheres. No decorrer do ano, várias atividades foram realizadas com o grupo de idosos. Uma das atividades destacadas referia-se ao levantamento de temas que os participantes gostariam de discutir; sugeriram temáticas inseridas no seu cotidiano, desde questôes de como lidar com a dependência química (um forte problema enfrentado pela comunidade, visto que vários adolescentes e jovens são usuários de álcool e outras drogas), bem como trouxeram temáticas em evidência na mídia naquele momento, a exemplo do cangaço e da ditadura militar. Assim, desenvolveu-se uma série de rodas de conversas que atendessem a tais temas, promovendo maior acesso à cultura e à história do País. Vale salientar que as rodas de conversa consistem em um método de trabalho que incentiva a participação e reflexão pela busca pelo diálogo entre os participantes, por meio de postura de escuta e circulação da palavra, bem como do uso de técnicas de dinamização de grupo, podendo ser utilizadas em diversos contextos (Afonso \& Abade, 2008). 
O Grupo das Gestantes foi constituído com base na listagem das gestantes existentes no Município, disponibilizada pela Secretaria Municipal de Saúde, e teve uma média de duração de dois meses. Contando com aproximadamente 15 participantes, os encontros eram realizados uma vez por semana, nas instalações do CRAS, onde as gestantes eram auxiliadas na confecção manual e artesanal do seu enxoval. Havia ainda a oferta de palestras socioeducativas realizadas por enfermeiros, psicólogo e assistente social. Quanto à participação do psicólogo, trabalhou-se o fortalecimento do vínculo mãe-bebê, a vida afetiva do casal durante o período da gestação, a preparação para a chegada do bebê e orientações referente ao seu desenvolvimento entre 0 e 6 meses.

No período em que transcorreu essa experiência, a Associação das Costureiras estava retomando suas atividades. Era um grupo composto por aproximadamente oito mulheres e tinha como objetivo formar uma cooperativa para a confecção de roupas. O CRAS cedeu o espaço para que elas pudessem se reunir e ofereceu também suporte de orientação visando a fortalecer as potencialidades do grupo. Vale salientar que suas reuniões não eram sistemáticas, aconteciam conforme a solicitação dos participantes. No único encontro em que a Psicologia pôde contribuir, optou-se por trabalhar o compartilhamento da responsabilidade no processo de reconstrução da Associação. Para isso, utilizou-se da técnica dos balóes, que consistiu em solicitar que os sujeitos supusessem que, dentro de cada balão, houvesse um problema que a Associação enfrentava e se movimentassem pela sala, suspendendo o seu balão, com o cuidado de não o deixarem cair. Após esse momento, instruía-lhes que fossem saindo aos poucos da grande roda e deixassem o seu balão sob a responsabilidade do grupo que ficou, e este teria de suspender os "balóes-problemas". Estes, cada vez mais numerosos, impossibilitavam o grupo de suspendê-los. A partir dessa técnica bastante simples, fez-se uma reflexão a respeito do engajamento de todos os componentes da Associação no enfrentamento de suas dificuldades, o que foi muito positivo, uma vez que as mulheres puderam pensar sobre o seu papel na organização de um espaço que vinha sendo construído por elas. Segundo a PNAS (Ministério do Desenvolvimento Social e Combate à Fome, 2004), é interessante ressaltar que o CRAS deve desenvolver serviços socioassistenciais de inclusão produtiva e oferecer um suporte aos projetos de geração de renda existente nos municípios.

Além disso, a equipe do PETI formou um grupo de mães e pediu ao CRAS que realizasse alguma participação. $\mathrm{O}$ grupo foi composto por mães as quais a equipe identificou que os vínculos familiares estavam fragilizados, composto por aproximadamente dez mães, e funcionava nas instalações do próprio PETI. Com esse grupo, objetivou-se realizar um trabalho sociofamiliar, atendendo às Orientações Técnicas sobre o Serviço de Convivência e Fortalecimento de 
Vínculos (Brasil, 2010). De acordo com esse documento, o envolvimento das famílias é fundamental para o êxito das atividades direcionadas ao fortalecimento de vínculos, ressaltando a importância de articulação com a proteção social básica. Para tanto, realizaram-se rodas de que conversas que visavam a trabalhar a relação entre pais e filhos, a fim de ajudá-los a construir estratégias de cuidado de não reprodução da violência. Para a construção das rodas de conversas, foi utilizado o material "Cuidar sem violência, todo mundo pode! Fortalecendo as bases de apoio familiares e comunitárias para crianças e adolescentes - Guia prático para famílias e comunidades" (Arruda, Zamora \& Barker, 2003).

O trabalho socioeducativo realizado com os grupos refletiu a concepção de sujeito defendida pela Psicologia comunitária, que "compreende o homem na sua totalidade histórica, em movimento e protagonista da sua história particular e coletiva, forjando relações cotidianas que podem contribuir para a construção de uma vida mais digna e humana" (Freitas, 1998, p. 8). Ou seja, uma perspectiva que insere o sujeito no processo de historicidade para compreender contextualmente a sua formação humana. Acredita-se que as temáticas trabalhadas com os grupos de mães, idosos, gestantes e a Associação das Costureiras contribuiu com a incorporação de processos de empoderamento de suas vidas, principalmente em relação à família e à comunidade.

\section{Articulação da rede de serviços e o seu fortalecimento}

$\mathrm{O}$ trabalho de articulação com as redes intersetorial e socioassistencial ocorreu por meio do desenvolvimento de oficinas junto a instâncias que desempenham uma forte atuação junto à população, com o intuito de fortalecer a rede dessa comunidade. Foram realizadas três oficinas, a primeira contou com a equipe gestora da educação, a segunda, com os agentes comunitários de saúde, e a terceira, com a equipe do Conselho Tutelar e os líderes da Pastoral da Criança.

A oficina foi intitulada "O CRAS precisa da Saúde, da Educação, da Pastoral da Criança, do Conselho Tutelar para a efetivação da garantia de direitos". Pretendiase com esse título demonstrar a necessidade de articulação do CRAS com outras instâncias para poder atuar na perspectiva da garantia dos direitos sociais. Em cada oficina, explicitou-se os objetivos do trabalho do CRAS, o público-alvo prioritário, os serviços oferecidos e os esclarecimentos sobre algumas restrições colocadas à atuação do psicólogo naquele espaço, principalmente em relação à psicoterapia, à reabilitação, ao acompanhamento de alunos com dificuldades de aprendizagem e à avaliação psicométrica (Conselho Federal de Psicologia [CFP], 2008; Conselho Federal de Serviço Social [CFSS] \& CFP Brasil, 2009), ao mesmo tempo em que eram trazidas as características do trabalho desenvolvido. 
Encerrava-se a oficina após a discussão de alguns estudos de casos que passaram pela instituição, em que os participantes foram convocados a pensar ações junto ao CRAS para solucionar as demandas apresentadas. Essa ação de fortalecimento da rede foi de fundamental importância quanto ao esclarecimento da atuação do psicólogo numa perspectiva comunitária. Destaca-se ainda que as oficinas foram realizadas com participantes que se encontravam em posição estratégica junto à comunidade (profissionais da Educação, agentes comunitários de saúde, líderes da Pastoral da Criança), o que pôde facilitar a divulgação e o esclarecimento da função do CRAS, bem como referenciar demandas que pudessem ser trabalhadas articuladamente.

\section{Sistematização das informações}

Por último, a sistematização das informaçôes caracterizou-se pelo levantamento dos casos que chegaram ao CRAS, a fim de elaborar um diagnóstico das principais problemáticas vivenciadas pela comunidade. Tal sistematização pôde ser um recurso potencial para aprimorar o trabalho técnico da equipe, principalmente por meio da oferta de novas ações que fossem adequadas às necessidades concretas das famílias. Essa ação também foi desenvolvida em diálogo com os pressupostos da Psicologia comunitária, entre estes, a importância de desenvolver intervenções que identificassem as vulnerabilidades da comunidade, sendo uma orientação dirigida ao desenvolvimento comunitário (Montero, 2004).

\section{Considerações finais}

A Assistência Social configura-se como um campo de trabalho de importância fundamental para se discutir a atuação do psicólogo, visto que o profissional se depara com um público-alvo que, ao longo do desenvolvimento histórico da profissão, esteve fora do seu escopo interventivo.

Compreende-se o CRAS como um espaço atravessado pelas contradições que marcam a política de Assistência Social. Tais contradições desdobramse no trabalho do psicólogo, exigindo que esse profissional tenha clareza dos limites e possibilidades da intervenção no campo do bem-estar social. Para tanto, considera-se imprescindível reconhecer o seu posicionamento ético-político e, a partir desse, enxergar as repercussões de sua ação no âmbito da comunidade.

Não se pretendeu aqui engessar a prática psicológica nesse espaço, mas lançar reflexões e apontar alguns caminhos possíveis a partir de um diálogo entre a Psicologia comunitária e a PNAS. Como se pôde perceber, muitas das ações desenvolvidas no estágio estiveram relacionadas à realidade local da comunidade 
e somente fazem sentido quando articuladas ao seu contexto social, político, econômico e cultural.

Por fim, compreende-se que o encontro do profissional de Psicologia com a comunidade tem o potencial de abrir caminhos para a sua prática. A atuação do psicólogo possibilita, nas limitações estruturais impostas pelo modo de produção capitalista, avançar na efetivação da garantia de direitos nas dimensões individual, familiar, grupal e comunitário, contribuindo para o fortalecimento das políticas sociais. 


\section{Referências}

Afonso, M. L. M. \& Abade, F. (2008). Para reinventar as rodas. Belo Horizonte: Rede de Cidadania Mateus Afonso de Medeiros. Recuperado a partir de http:// www.ufsj.edu.br/portal-repositorio/File/lapip/PARA_REINVENTAR_AS_ RODAS.pdf

Arruda, S., Zamora, M. H. \& Barker, G. (2003). Cuidar sem violência, todo mundo pode!: fortalecendo as bases de apoio familiares e comunitárias para crianças e adolescentes: guia prático para famílias e comunidades. Rio de Janeiro: Instituto Promundo/Ciespi. Recuperado a partir de http://promundoglobal.org/wpcontent/uploads/2014/12/Cuidar-sem-violencia-todo-mundo-pode.pdf

Brasil. Ministério do Desenvolvimento Social e Combate à Fome. (2004). Política Nacional de Assistência Social. Brasília: MDSCF.

Brasil. Ministério do Desenvolvimento Social e Combate à Fome. (2006). Orientaçóes para o acompanhamento das famílias beneficiárias do Programa Bolsa Família no âmbito do Sistema Único de Assistência Social - SUAS [Versão Preliminar]. Brasília: MDSCF.

Brasil. Ministério do Desenvolvimento Social e Combate à Fome. (2009). Orientaçôes técnicas: Centro de Referência da Assistência Social-CRAS. Brasília: MDSCF.

Brasil. Ministério do Desenvolvimento Social e Combate à Fome. (2010). Orientaçôes técnicas sobre o Serviço de Convivência e Fortalecimento de Vinculos (prioridades para crianças e adolescentes de 6 a 15 anos integrantes do programa de erradicação do trabalho infantil) [Versão Preliminar]. Brasília: MDSCF.

Bremaeker, F. E. J. (2010). A pobreza em nivel municipal. Salvador: Transparência Municipal. (Estudo Técnico, 99). Recuperado a partir de http://www.oim. tmunicipal.org.br/abre_documento.cfm?arquivo=_repositorio/_oim/_ documentos/F597E448-92A3-E540-C16935B3135811B522022010091237. pdf\&i $=970$

Conselho Federal de Psicologia. (2008). Referência técnica para atuação do(a) psicólogo(a) no CRAS/SUAS. Brasília: CFP.

Conselho Federal de Serviço Social \& Conselho Federal de Psicologia. (2007). Parâmetros para atuação de assistentes sociais e psicólogos(as) na Política de Assistência Social. Brasília: CFSS; CFP. 
Couto, B. R. (2010). O direito social e a assistência social na sociedade brasileira: uma equação possivel? São Paulo: Cortez.

Freitas, M. F. Q. (1998). Inserção na comunidade e análise de necessidades: reflexōes sobre a prática do psicólogo. Psicologia: Reflexão e Crítica, 11(1), 175189.

Gracia, E. (2007). El apoyo social a domicilio: la prevención del riesgo social en familias mediante visitas al hogar. In A. A. Blanco \& J. M. Rodríguez (Orgs.), Intervención psicosocial. (pp. 301-322). Madrid: Pearson Educación.

Instituto de Pesquisa Econômica Aplicada. (2010). Objetivos de desenvolvimento do milênio: relatório nacional de acompanhamento. Brasília: IPEA.

Kosik, K. (2002). Dialética do concreto. São Paulo: Paz e Terra.

Lei Federal n. ${ }^{\circ}$ 8.742, de 7 de dezembro de 1993. Dispóe sobre a organização da Assistência Social e dá outras providências. Brasília: Presidência da República. Recuperado a partir de http://www.planalto.gov.br/ccivil_03/leis/L8742.htm.

Mioto, R. C. T. (2008). Família e políticas sociais. In I. Boschetti, E. R. Behring, S. M. M. Santos \& R. C. T. Mioto (Orgs.), Política social no capitalismo: tendências contemporâneas. (pp. 130-148). São Paulo: Cortez.

Montero, M. (2004). Que és la psicología comunitaria. In M. Montero (Org.), Introducción a la Psicologia comunitaria: desarrolo, conceptos y procesos. (pp. 6787). Buenos Aires: Paidós.

Paiva, B. A. (2006). O SUAS e os direitos socioassistenciais: a universalização da seguridade social em debate. Serviço Social \& Sociedade, 87(27), 5-23.

Paulo Netto, J. (2001). Cinco notas a propósito da "questão social". In J. Paulo Netto, Capitalismo monopolista e Serviço Social. (pp. 151-176). São Paulo: Cortez.

Santos, W. G. (1987). A trágica condição da política social. In S. H. Abranches, W. G. Santos \& M. A. Coimbra (Orgs.), Política social e combate à pobreza (2a ed., pp. 33-63). Rio de Janeiro: Jorge Zahar.

Yamamoto, O. H. (2003). Questão social e políticas públicas: revendo o compromisso da Psicologia. In A. M. B. Bock (Org.), Psicologia e o compromisso social. (pp. 37-54). São Paulo: Cortez. 